\title{
Prosodic rhythm and African American English $^{\star}$
}

\author{
Erik R. Thomas and Phillip M. Carter \\ North Carolina State University / Duke University
}

\begin{abstract}
Prosodic rhythm was measured for a sample of 20 African American and 20 European American speakers from North Carolina using the metric devised by Low, Grabe and Nolan (2000), which involves comparisons of the durations of vowels in adjacent syllables. In order to gain historical perspective, the same technique was applied to the ex-slave recordings described in Bailey, Maynor and Cukor-Avila (1991) and to recordings of five Southern European Americans born before the Civil War. In addition, Jamaicans, Hispanics of Mexican origin who spoke English as their L2, and Hispanics speaking Spanish served as control groups. Results showed that the North Carolina African Americans and European Americans were both quite stress-timed overall, with no significant difference between them. Spanish emerged as solidly syllable-timed, while Jamaican English and Hispanic English were intermediate. The ex-slaves were significantly less stress-timed than either younger African Americans or European Americans born before the Civil War. This finding suggests that African American English was once similar to Jamaican English in prosodic rhythm.
\end{abstract}

Keywords: African American English, AAE, prosodic rhythm, stress-timing, syllable-timing, diachronic change, suprasegmental variation, prosodic variation, Southern English

\footnotetext{
* This research was supported by NSF grant BCS-0213941. We thank Walt Wolfram for his support in amassing the NCLLP corpus, as well as the many fieldworkers who collected the data, especially Kirk Hazen and James Peterson (Warren County), Elaine Green (Hyde County), Clare Dannenberg, Roscoe Johnson, and James Peterson (Robeson County), and Beckie Moriello (Siler City). We are grateful to Peter L. Patrick for providing us with the Jamaican recordings. We also thank Guy Bailey for supplying us with the recordings of the ex-slaves and the European American Southerners born before the Civil War, and Michael Montgomery for sending Bailey the recording of the speaker from the Smoky Mountains of Tennessee some years ago.
} 


\section{Introduction}

As is well known, few topics have received as much attention from sociolinguists working in the variationist tradition as African American English (AAE) (Schneider 1996). Surely, interest in AAE has, in part, been generated and maintained by debates in the public forum such as the Ann Arbor (Michigan) controversy of 1979 and the Oakland (California) School Board decision in 1996, as well as by a number of somewhat polemic debates among sociolinguists about the origins of AAE, its trajector(ies) of change, and more recently, the extent to which it varies regionally. But despite the wealth of published material on AAE from the past 40 years of sociolinguistic scholarship, the research has, with few exceptions, been overwhelmingly focused on a finite set of morphosyntactic and consonantal features (Ash 2003), thus inhibiting a more holistic description of AAE and restricting the scholarly development of the debates surrounding the variety.

In the present study, we investigate a previously unexamined variable in AAE: prosodic rhythm, or timing, a variable often viewed as consisting of the opposing types known as "syllable-timing", "stress-timing", and "mora-timing". We situate this work primarily within the tradition of variationist study on AAE but also within the emerging body of research on prosodic rhythm found in the phonetics and sociolinguistic literatures. This study, then, proceeds on two fronts, descriptive and theoretical. The first is to provide a descriptive account of the general rhythmic characteristics of AAE that focuses primarily on the role of prosody as a possible distinctive dialect feature of AAE with secondary and tertiary foci on comparative and diachronic accounts of prosodic rhythm in AAE. Subsequently, we argue that the hegemony of a finite set of morphosyntactic and phonological features, along with the concomitant marginalization of non-segmental features, severely scales down the descriptive power of sociolinguistics and, correspondingly, distorts our overall understanding of language variation. We hope that our analysis promotes broader analyses of AAE that incorporate previously unexamined or barely examined variables.

\section{Approaches to the analysis of rhythm}

Rhythm is a previously unanalyzed variable in AAE, though it is not one that has never been considered. Spears (1988), for instance, pointed to it as a possibly salient feature of AAE. However, the main obstacle to studying rhythm is that, until recently, there was no reliable way to measure it acoustically. In addition, 
rhythm was traditionally viewed as an absolute variable, with languages being clearly classifiable as syllable-timed, stress-timed, or mora-timed, whereas recent findings have indicated that the different types grade into each other.

It was apparently Pike (1945) who first coined the terms "syllable-timing" and "stress-timing" to describe the rhythm patterns found, respectively, in Spanish and English. These phenomena were already widely known, however (see the historical reviews in Dauer 1983, and in Fought and Fought 2002). Abercrombie (1967) later made much of the distinction, and his treatment has served as something of a standard definition - and a point of contention - ever since. Syllable-timing refers to the situation in which, supposedly, each syllable has approximately the same duration. Conversely, stress-timing refers to the pattern in which each syllabic foot reputedly has about the same duration, so that the duration from one stress to the next is approximately the same. Subsequently, mora-timing was added to describe languages such as Japanese in which each mora has roughly the same duration.

This neatly packaged theory was upset when it was shown that inter-stress durations do not differ significantly between syllable-timed and stress-timed languages and that syllable durations differ greatly in syllable-timed languages (e.g. Roach 1982; Wenk and Wiolland 1982; Dauer 1983; Borzone de Manrique and Signorini 1983). As a result, attempts to measure timing patterns physically foundered. Dauer (1983) concluded that the differences between timing types were functions of the phonological structures of languages - whether reduced syllables occurred, how word stress operated, and the consonantal structure of syllables - and did not reflect any intrinsic timing patterns in the languages themselves. For example, the frequent syllable reduction and the wide variety of syllable types in English make it seem stress-timed, while the general absence of syllable reduction in most dialects of Spanish and a strong tendency toward CV syllables in all dialects make Spanish seem syllable-timed.

Another development occurred when it was realized that the different timing patterns represented a continuum, rather than absolute differences (Miller 1984; Ramus, Nespor and Mehler 1999: 268-9). Languages that had been regarded as archetypes of syllable-timing (e.g. Spanish and Italian) and stresstiming (e.g. English and Dutch) were recognized now simply as languages with especially well-defined timing characteristics. Some languages that show mixed characteristics, such as Catalan, which exhibits simple syllable types but also syllable reduction, and Polish, with complex syllable types but no reduction, could then be classified as intermediate.

Ramus, Nespor and Mehler (1999) developed a way to classify the rhythm of language based on three continuous variables: the proportion of the duration 
of a sentence taken up by vowels, the standard deviation of the durations of the vocalic intervals, and the standard deviation of the durations of the consonantal intervals. In this approach, they followed Dauer's (1983) assertion that timing is a consequence of the phonology of a language. They analyzed sentences read by speakers of eight languages, including two stress-timed languages (English and Dutch), three syllable-timed languages (French, Italian, and Spanish), one mora-timed language (Japanese), and the mixed languages Catalan and Polish. The different groups of languages separated out well when all three variables were taken into account and they concluded, like Dauer (1983), that rhythm is a consequence of phonological structure.

However, not all researchers have concurred with Ramus, Nespor and Mehler (1999). Gut et al. (2002) compared three West African languages that exhibit different phonotactic constraints, Ibibio from Nigeria, and Anyi and Ega from the Ivory Coast. In Ibibio, consonant clusters are infrequent and always have a semivowel as their second member, but coda consonants occur commonly. In Anyi, consonant clusters are common, but coda consonants are prohibited. Ega allows both consonant clusters and coda consonants, though the latter are rare. Gut et al. found that, in spite of the structural differences, all three are syllable-timed. In their view, rhythm is thus not entirely dependent on the phonotactic constraints that a language exhibits.

Gut et al's (2002) findings suggest a need to develop a method that measures rhythm directly. In fact, such a method had previously been created. Low and Grabe (1995) and Low, Grabe and Nolan (2000) devised what they called the "Pairwise Variability Index", or "PVI", to measure rhythm. PVI involves comparisons of the durations of vocalic segments in adjacent syllables. The formula consists of the absolute value of the difference between adjacent syllables divided by the mean of the two syllables. The resulting quotients are then averaged for an entire utterance, such as a sentence, and multiplied by 100. An advantage of comparing adjacent syllables is that it controls for overall speaking rate. Low and Grabe (1995) and Low, Grabe and Nolan (2000) applied it to a comparison of British and Singapore English using sentences read by speakers of each variety. Singapore English has often been characterized as more syllable-timed than most other varieties of English, including British English. The PVI formula achieved the result of showing that Singapore English is indeed more syllable-timed than British English. Furthermore, Low, Grabe and Nolan (2000) demonstrated that PVI provided a better gauge of rhythm than the metrics that Ramus, Nespor and Mehler (1999) had proposed, once again suggesting that timing is at least partially independent of phonological structure. 
Deterding (2001) also compared Singapore English with British English. His methods differed in several details from those of Low, Grabe and Nolan (2000), however. First, he used conversational speech instead of read sentences. A number of studies, e.g. Howell and Kadi-Hanifi (1991) and Swerts, Stangert and Heldner (1996), have noted important prosodic differences between read and spontaneous speech, and, accordingly, Deterding preferred to examine more naturalistic speech, in contrast to Low and Grabe (1995) and Low, Grabe and Nolan (2000). Second, he omitted utterance-final syllables from consideration because they are typically lengthened (e.g. Klatt 1975). Third, he measured entire syllables instead of just the vowels within syllables. One of his justifications for doing so was that conversational speech exhibits frequent syllabic consonants, such as the second syllable of fasten, that the Low, Grabe and Nolan (2000) method would omit. However, measuring entire syllables created other problems for Deterding because it is not always clear which syllable certain intervocalic consonants should be assigned to. Fourth, he used a different formula, which he called the "Variability Index" (VI). It involved dividing the absolute value of the difference between durations of adjacent syllables by the average of those values for the entire utterance, and then computing the mean of those quotients for each utterance. In spite of the methodological differences between Deterding (2001) and Low, Grabe and Nolan (2000), Deterding confirmed Low, Grabe and Nolan's finding that Singapore English is more syllabletimed than British English.

It should be noted that, since the majority of Singaporeans have some variety of Chinese or another Asiatic language (e.g. Malay) as their first language, and even though many younger Singaporeans are now acquiring English as a first language, Singapore English has thus far existed primarily as a second language. The syllable-timing of Singapore English, then, appears to be an interference or substrate effect from Chinese. Similarly, Gut (2002) and Udofot (2003) report that some speakers of Nigerian English, which is also a second language for the vast majority of its speakers, show more syllable-timing than speakers of British English. Various studies (e.g. Bond and Fokes 1985; Mochizuki-Sudo and Kiritani 1991; Nguyen 2003; Carter 2004, 2005a, 2005b) have found that native speakers of syllable- and mora-timed languages, including Malaysian, Vietnamese, Spanish, and Japanese, experience difficulty learning the stress-timed pattern of English. The most pervasive difficulty that such speakers experience is in attaining the proper degree of syllable compression as unstressed syllables are added to syllabic feet.

Clearly, syllable-timing can appear as an interference feature in the speech of second language learners of English. It thus seems plausible that it could be 
maintained as a substrate feature in cases of language transfer. One study of Chicano English in California, Fought and Fought (2002), suggests that it can. Using the PVI formula of Low, Grabe and Nolan (2000) with conversational speech from sociolinguistic interviews conducted in the field, they found that California Chicano English is more syllable-timed than California Anglo English. Oddly, however, the difference seemed to apply only to the first five syllables of an utterance.

Language contact is not the only situation in which rhythm analysis can be applied profitably. Spencelayh (2001) compared local dialects from three cities in northern England, Newcastle, York, Derby, and one in Scotland, Buckie. Like Fought and Fought (2002) and Carter (2004), Spencelayh used Low, Grabe and Nolan's PVI formula with conversational speech. The findings indicated that the two southernmost cities, York and Derby, grouped together at the stresstimed end of the UK continuum. Buckie appeared at the syllable-timed end of the continuum, and Newcastle was intermediate. However, there was a great deal of individual variation among speakers. In addition, the differences were most likely due to presence or absence of the Scottish Vowel Lengthening Rule, which causes vowels to be lengthened morpheme-finally and before certain consonants.

\section{Data used for this study}

The main body of data that we present here is analyses that we undertook of interviews collected under the auspices of the North Carolina Language and Life Project (NCLLP) at North Carolina State University. The NCLLP has conducted ethnographic surveys of a variety of communities across North Carolina, as depicted in Figure 1, as well as a few extralimital communities. These interviews consist of conversational speech by people of all age groups. We thus followed Deterding (2001) insofar as we used spontaneous speech. Sociolinguistic interviews were conducted by numerous fieldworkers, including (mainly for Hyde County and Raleigh) the two authors. All or nearly all of the interviews were conducted using Marantz tape recorders, model PMD 221, but a variety of microphone models (usually either a Shure, Model SM 48, or a PZM Sound Grabber, Model 12 SG) were used. Settings for the interviews varied, though most took place at speakers' homes. For this study, we focused on African Americans and European Americans from three rural counties in North Carolina: one coastal (Hyde County), one along the Virginia border (Warren County), and one along the South Carolina border (Robeson County). 


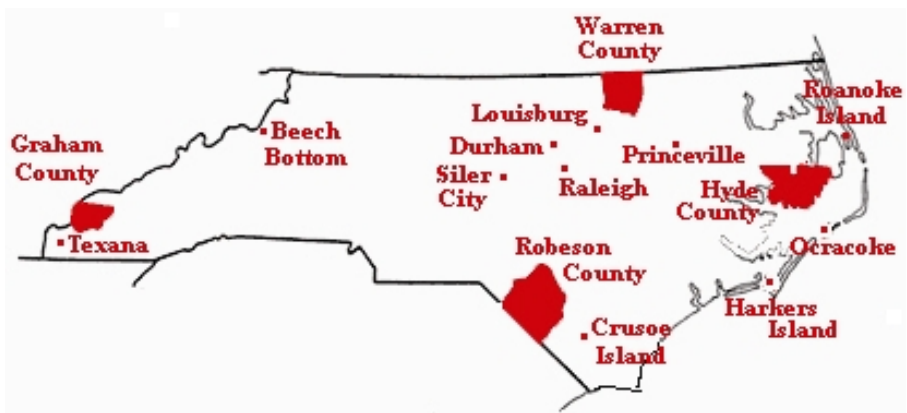

Figure 1. Locations of North Carolina Language and Life Project Communities, including communities used for this study

These three counties were the NCLLP communities with the most substantial numbers of interviews with speakers of both ethnic groups.

From that corpus, we chose ten African Americans and ten European Americans born during the period from 1896 to 1931, as well as ten speakers from each ethnicity who were born during the period from 1961 to 1985. Hence, our analysis of contemporary AAE and European American English (EAE) is based on interviews with forty NCLLP speakers. Within each birth cohort / ethnicity group, we included six females and four males. Speakers were selected not on the basis of any linguistic features, but instead based on such factors as the sound quality of the recording, the length of the interview, and the local nativity of the speaker. For each birth cohort / ethnicity cell, we included at least one female and one male from each of the three counties.

We also analyzed smaller numbers of interviews from various other groups to provide control groups for the rhythm data and to provide information on earlier AAE and EAE. For one control, we analyzed interviews with Hispanic L2 speakers of English from two additional NCLLP communities in North Carolina, Raleigh and Siler City. Their L1, Spanish, is syllable-timed (e.g. Pike 1945, though see Miller 1984), and as would be predicted from studies of L2 acquisition of English (Bond and Fokes 1985; Mochizuki-Sudo and Kiritani 1991; Nguyen 2003) and from the Fought and Fought (2002) study, we expected their speech to be more syllable-timed than that of native English speakers. As another control, we analyzed the Spanish spoken by a sample of Hispanics in Raleigh, some of whom were also used in the Hispanic English sample. We expected that measurements of Spanish would show a strong syllable-timing pattern.

Perspectives on the early AAE and EAE were provided by three other groups of recordings. The first are the ex-slave recordings from the corpus 
featured in Bailey, Maynor and Cukor-Avila (1991). We analyzed all speakers for whom transcriptions were published in that book except for Charlie Williams, who was born in Liberia, and the unnamed woman in the Joe McDonald interview, who did not speak enough to allow analysis. We added two speakers who are mentioned in the introduction of Bailey, Maynor and Cukor-Avila (1991): "Mrs. Williams", who was a North Carolina native but lived in Virginia when she was interviewed, and George Johnson, identified as "Colored Fellow" in Bailey, Maynor and Cukor-Avila (1991) and a native of western Mississippi. We also analyzed the speech of Wallace Quarterman, who spoke Gullah, but reserved a special category for him. This gave us ten ex-slaves besides Quarterman. The question of the typicality or representativeness of these speakers among African Americans of this time period is addressed in Rickford (1991). Essentially, it is impossible to know with certainty, though the speakers represent a range of characteristics, including males and females, field hands and house servants, and different geographical regions.

In addition, we were also able to analyze the speech of five European American Southerners who were born before the Civil War, all of whom were male. The speakers in this group were from southeastern Virginia, the Smoky Mountains of Tennessee, south-central Tennessee, central Arkansas, and the Brazos valley of Texas, respectively. All but the speaker from the Smoky Mountains lived in areas with high African American populations and for that reason serve as reasonable counterparts to the ex-slaves. The Smoky Mountains had virtually no African Americans, however. Nevertheless, his speech is useful as a point of reference for the four other pre-Civil War European Americans in case they showed any influence from African American rhythm. This small sample can hardly be considered representative of Southern European Americans of that period, especially considering that it includes no women. They represent a wide geographical spread, however, and some variation in class, as the Virginian was upper-class and the other four were either working- or middle-class.

Finally, we analyzed recordings of four speakers of Jamaican English from Kingston, Jamaica. We chose to analyze this group for a number of reasons. First, Jamaican English has an indisputable creole origin. Moreover, Caribbean creoles are often regarded as more syllable-timed than varieties of English with no creole history (Wells 1982). It thus provides a valuable point of reference. 


\section{Methods of analysis}

We chose to use the PVI formula developed by Low, Grabe and Nolan (2000), though with some modifications from the way they applied it. In addition to analyzing spontaneous, conversational speech instead of read speech, we deviated in three other ways. First, we dispensed with multiplying the mean of the quotients by 100. Second, we averaged all the PVI quotients measured for a particular speaker, rather than computing a mean for each utterance. Using an overall mean works better for spontaneous speech, for which utterances vary widely in length, the determination of the beginnings and endings of utterances is often debatable, and there are numerous false starts and other disfluencies. Third, we omitted all feet falling immediately before a pause, a hesitation marker such as $u h$, a repair, or a restart. This specification controlled for phrase-final lengthening, which, we found, commonly occurs in all of those situations. Utterances that ended with a repair or a restart were included - except, of course, for their final foot - because they are a pervasive part of naturalistic speech and excluding them would have introduced an element of artificiality to the analysis.

The PVI procedure, which examines only vowel durations, proved more practical than Deterding's (2001) method of comparing the duration of entire syllables for a number of reasons. One, which Deterding noted, is that there is often uncertainty about the assignment of certain intervocalic consonants, such as the / $t$ / in letter, to the preceding or following syllable. Another difficulty is that it is generally impossible to determine the onset of an utterance-initial voiceless stop. Yet another problem is that ambient noise in the field recordings we used rendered the delimitation of some consonants impossible. A solution to the ambient noise problem might have been to measure from the onset of one vowel to the onset of the next instead of from syllable onset to syllable onset. However, like Deterding's method, that procedure conflates vowel duration and consonant duration, masking possible differences in how each one operates. In any case, the results from our control groups indicated that vowel durations provided adequate differentiation.

Most of the recordings were digitized at a sampling rate of exactly $20 \mathrm{kHz}$, with lowpass filtering at $8 \mathrm{kHz}$. Because of equipment failure toward the end of the project, a few recordings had to be digitized at a sampling rate of 44.1 $\mathrm{kHz}$, with lowpass filtering at $20 \mathrm{kHz}$. The difference in sampling rates makes no difference for our analyses, which depended upon information contained in frequencies below $3 \mathrm{kHz}$. Spectrograms were generated in PRAAT using a window length of $5 \mathrm{~ms}$ and a viewing range from 0 to $5 \mathrm{kHz}$. 
Careful transcripts showing all pauses were prepared for each interview that was analyzed. Determination of what constitutes a pause is open for interpretation. Butterworth (1980) notes that $200 \mathrm{~ms}$ has become a standard minimum threshold for a pause in studies of pauses. The primary reason for that figure, according to Butterworth, is that a stop often fills that much time. However, shorter pauses do occur, even when there is no adjacent stop. Thus we counted as a pause any break in speech that impressionistically sounded like a pause, which proved to be breaks over approximately $70 \mathrm{~ms}$. Spectrograms revealed even shorter breaks, usually consisting of glottal stops, but they did not give the impression of a pause.

For all but three interviews, the first five minutes of the interview were excluded from analysis. This stipulation allowed for a period of adjustment to the interview situation by the speaker. The three exceptions were all archival recordings that were shorter than five minutes: the ex-slaves Joe McDonald and Alice Gaston and the European American from Arkansas. For those interviews, we began analysis at the beginning of the recording. Otherwise, measurement ordinarily commenced at the five-minute mark. All utterances by the speaker being analyzed with at least one pair of adjacent syllables not in a disallowed foot were measured from that point until a sufficient number of PVI scores was attained. We determined at least 200 PVI quotients for each speaker, a number sufficiently large that deviations due to segmental factors, such as intrinsically longer or shorter vowels (Peterson and Lehiste 1960) or the voicing of the following consonant (e.g. House and Fairbanks 1953) were averaged out. Both authors took part in the measurements, with each usually contributing to measurements of a particular speaker, in order to control for possible differences in practices between the authors. All vowels, including diphthongs, were treated in the same way. Thus, in a word such as hide, the /aI/ was considered to be the vowel, with no distinction between nucleus and glide. In most cases, determination of where to measure was straightforward. Vowels were taken to be the period between the onset and offset of vowel formants, usually coinciding with periodicity, and beginning and cessation of F2 served as the main cue. As a result, formant transitions for obstruents were counted as part of the vowel. For devoiced vowels, which occurred infrequently, a recognizable formant pattern in the aspiration served as the cue to vowel duration. A burst associated with a preceding stop was not included. Nasals and, usually, a preceding /1/ could be treated similarly because of the sudden break in the formant pattern between the nasal or lateral and the vowel. A preceding approximant or two adjacent vowels required another procedure. For preceding /w/ and /r/, the boundary was taken as the point at which splicing the signal made the part of the signal after the splice sound 
impressionistically like [b] instead of like an approximant. Preceding /j/ and instances of preceding /l/ without a clean formant shift were treated in much the same way, with the boundary taken as the point at which the signal after the splice no longer sounded like consonantal [j] or [t]. For adjacent vowels, the boundary was placed at the point at which the signal to the left sounded impressionistically like the preceding vowel and that to the right sounded like the following vowel, which was often correlated with a shift in the $\mathrm{F}_{0}$ contour.

Syllable-coda / $/ /$ and / $/$ / were treated as glides and thus as part of the "vowel". The normal pattern in North Carolina English is for coda /l/ to be vocalized to [o], in which case it forms a true diphthong. Coda $/ \mathrm{r} /$ phonetically resembles a vowel except for its low $\mathrm{F}_{3}$. Treating it as a glide has two other advantages. One is that the long transitions and large degree of coarticulation between a vowel and a coda $/ \mathrm{r} /$ render placement of a division between them arbitrary. The other advantage has to do with the variation in $r$-fulness within our sample. In general, European Americans from Hyde and Robeson Counties, young European Americans from Warren County, and most African Americans from Hyde County were $r$-ful in words such as there, hard, and porch, while African Americans from Robeson and Warren Counties and older European Americans from Warren County were generally $r$-less in such words. Counting coda $/ \mathrm{r} /$ as a glide meant that a given word was treated the same whether a speaker was $r$-less or $r$-ful: For example, in porch, everything between $\left[\mathrm{p}^{\mathrm{h}}\right]$ and $\left.[\mathrm{t}]\right]$ was measured as the vowel regardless of whether it was produced as [or], [oə], or [ou].

Intervocalic $/ \mathrm{r} /$ and $/ \mathrm{l} /$ were problematic. For $/ \mathrm{l} /$, the decisions about which syllable to assign an intervocalic liquid to depended on morphology. As a result, in fell off, the /l/ would be assigned to the prior syllable and thereby be counted as part of the vowel, while in fellow or felonious it would be assigned to the following syllable and not count as part of any vowel. In caller, the /1/ would be part of the first syllable because of the morpheme boundary, but in collar it would be part of the second syllable. A justification is that the morpheme boundaries may affect phonological mergers. For example, speakers who merge $/ \mathrm{a} /$ and $/ \mathrm{J} /$, as in cot and caught, may still distinguish caller and collar as [' $\left.\mathrm{h}^{\mathrm{h}} \mathrm{ot}_{\boldsymbol{1}}\right]$ and [' $\left.\mathrm{k}^{\mathrm{h}} \mathrm{a}_{\uparrow}\right]$, respectively. For $/ \mathrm{r} /$, the decision was based mainly on stress. When the preceding vowel was stressed and the following vowel was unstressed, as in parents or sorry, the / $\mathrm{r}$ / was assigned to the preceding syllable and counted as part of the vowel in that syllable. When the preceding vowel was unstressed and the following vowel was stressed, as in arrive or forensic, the $/ \mathrm{r} /$ was assigned to the following syllable and not counted as part of a vowel. If both syllables were unstressed, as in Hatteras or literate, the /r/ was assigned to the preceding syllable unless a word boundary intervened. Elision of the first 
unstressed vowel, as in asp'rin for aspirin, made the decision moot because there no longer was a preceding unstressed syllable. When both syllables were stressed, as in Leroy or far out, the decision was based on morphology. Justification for the criteria for intervocalic / $\mathrm{r} /$ can be found in the allophonic variants of /r/ that occur in American English. In syllable onsets, /r/ is normally pronounced with strong lip rounding, while in codas it is pronounced without rounding, even after a rounded vowel. Rounding occurs in cases such as arrive and Leroy for which we assigned the $/ \mathrm{r} /$ to the following syllable, but not in cases for which we assign the $/ \mathrm{r} /$ to the preceding syllable. Moreover, in words such as Hatteras and aspirin for which speakers vary between three-syllable and two-syllable pronunciations, the $/ \mathrm{r} /$ is unrounded in the three-syllable form, in which it is intervocalic, but is automatically rounded in the two-syllable form, in which it becomes part of a syllable onset. Nevertheless, words with intervocalic liquids occurred infrequently enough to make little impact on the overall score for an individual speaker.

Syllabic consonants were considered to be the nuclei of their respective syllables and thus were measured as the "vocalic" portion. Thus, when and was pronounced as $[n]$, the duration of the syllabic nasal was measured, but when it was pronounced as [ən], only the duration of [ə] was measured. When speaking English, the speakers were fairly consistent in producing such sequences as syllabic nasals after alveolar consonants and as [ən] after other sounds. /m/ and /y/ were also occasionally produced as syllabic consonants. /l/ and /r/ are ordinarily either syllabic or completely vocalized when they appear in rhymes of unstressed syllables in English, so the duration of the entire syllabic portion of such syllables was measured.

A few modifications were necessary for analysis of rhythm in Spanish. Spanish diphthongs, as in hay /ai/, were treated as a single vowel. When diphthongization occurred across a word boundary, as in la historia, it was still treated as a single vowel. However, in instances of hiatus, where adjacent vowels in contiguous words were produced independently, both vowels were analyzed separately. Determination of whether diphthongization occurred was made on a case-by-case basis. Diphthongization was not regarded as possible when either the first or second high, closed vowel $(/ \mathrm{i} /, / \mathrm{u} /)$ in a contiguous vowel pair constituted a stressed syllable. Thus, diphthongization was not considered to occur in oí, for which $i$ is stressed, but hoy /oi/ was regarded as a diphthong. Similarly, ía was treated as non-diphthongal in María, but ia was considered a diphthong in historia, whose primary stress is on the penultimate syllable, tó. This method was applied to all 14 vowel combinations that potentially result in diphthongization. Spanish /r/ and /l/ differ phonetically from English /r/ and 
/l/ and never behave like glides. Hence, postvocalic/r/ and /l/ in Spanish were never analyzed as part of the "vowel."

Although Fought and Fought (2002) found that the first five syllables in an utterance showed different rhythmic patterns than later syllables, no such effect was apparent in our data. This lack of differentiation occurred for all of our speaker groups, including the Hispanic L2 English speakers. For that reason, we included both earlier and later syllables from an utterance in our PVI calculations.

\section{Results}

Median PVI values for each speaker are plotted against the speakers' years of birth in Figure 2. We chose to show median values instead of means because the distribution of PVI values for any speaker is skewed and the median provides a better gauge of the center of distribution of PVI values. Means are almost always higher than medians in our data. Nevertheless, the relative distributions of PVI values for the different demographic groups we analyzed would not have differed if we had used mean values.

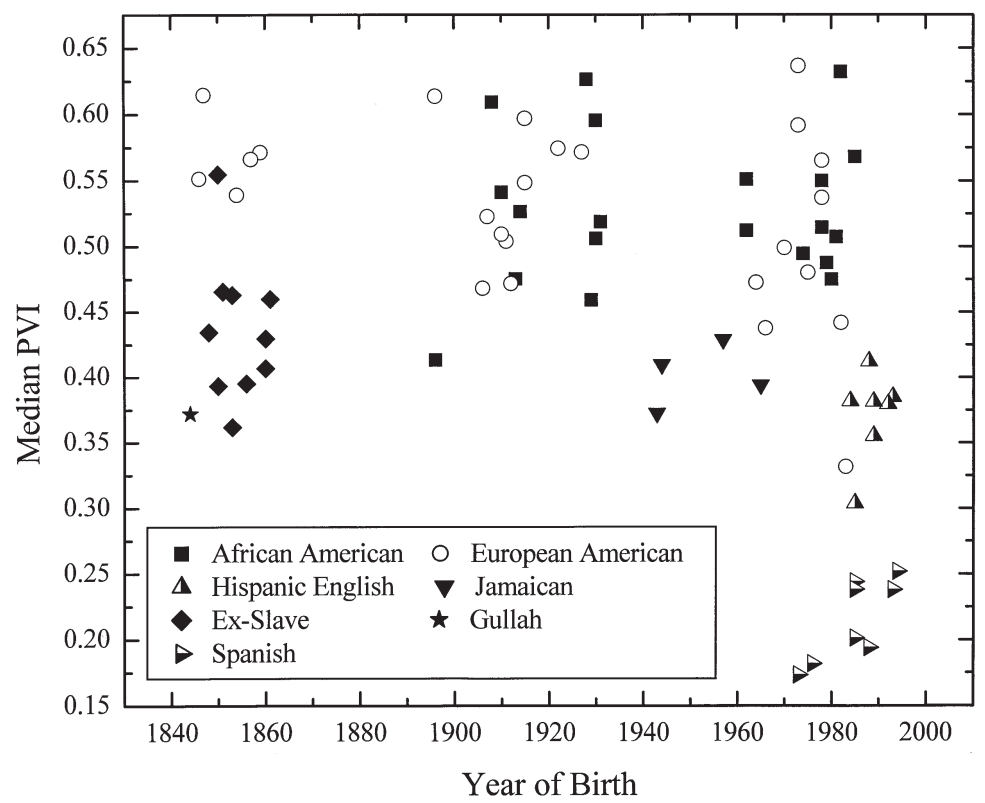

Figure 2. Median PVI scores for all speakers analyzed 
A number of trends are evident in the graph. As expected, the Spanish PVI scores were the lowest, with median values in the neighborhood of 0.2. The highest scores were those of European Americans and of African Americans born after 1900, most of which ranged between 0.45 and 0.65. One notable exception was a young European American female from Warren County whose median score was 0.3316 . She was a college preparatory school student and her speech may reflect a style adopted by some adolescent girls. It is characterized by an unusually small degree of temporal reduction of unstressed syllables as well as by intonational patterns that can strike listeners as disdainful. In between the PVI scores for Spanish speakers and those for most L1 English speakers were the scores for Hispanic L2 English and Jamaican English, which mostly fell near 0.4. It may not be surprising that Hispanic L2 English showed scores intermediate between Spanish and L1 English. The scores of the Jamaicans reflect the fact that Caribbean Anglophone speech is often described as being more syllable-timed than other varieties of English (see the discussion in Wells 1982: 572). Median PVI values for the ten ex-slaves are clustered between 0.35 and 0.47 , a range that also includes the scores of the Jamaicans and all but one Hispanic L2 English speaker, except for one outlier - the score of Joe McDonald - that occurs well within the values shown by contemporary African Americans and European Americans. The lone North Carolinian among the ex-slaves, Mrs. Williams, lies well within the main distribution of ex-slave PVI scores, with a median PVI value of 0.4296 .

A statistical comparison of the different demographic groups appears in the bar graph in Figure 3. The bars show mean values of the median PVI scores for all speakers in each group. Here, the European Americans born before the Civil War are separated from other European Americans. 95\% confidence intervals are included for each bar. The overall position of the different groups relative to each other is the same as in Figure 2. In general, the groups fall into three categories. African Americans (excluding ex-slaves), European Americans born after the Civil War, and Europeans born before the Civil War show the highest scores, with broad overlap of their confidence intervals. Ex-slaves, Jamaicans, and Hispanic L2 speakers of English form another category, also showing broad overlap in their confidence intervals. Finally, Spanish speakers by far show the lowest scores, with no overlap in their confidence interval with any other group.

The wide overlap between confidence intervals of the European Americans and African Americans from the North Carolina sample indicates that rhythm - at least the degree of stress-timing vs. syllable-timing - is not a 


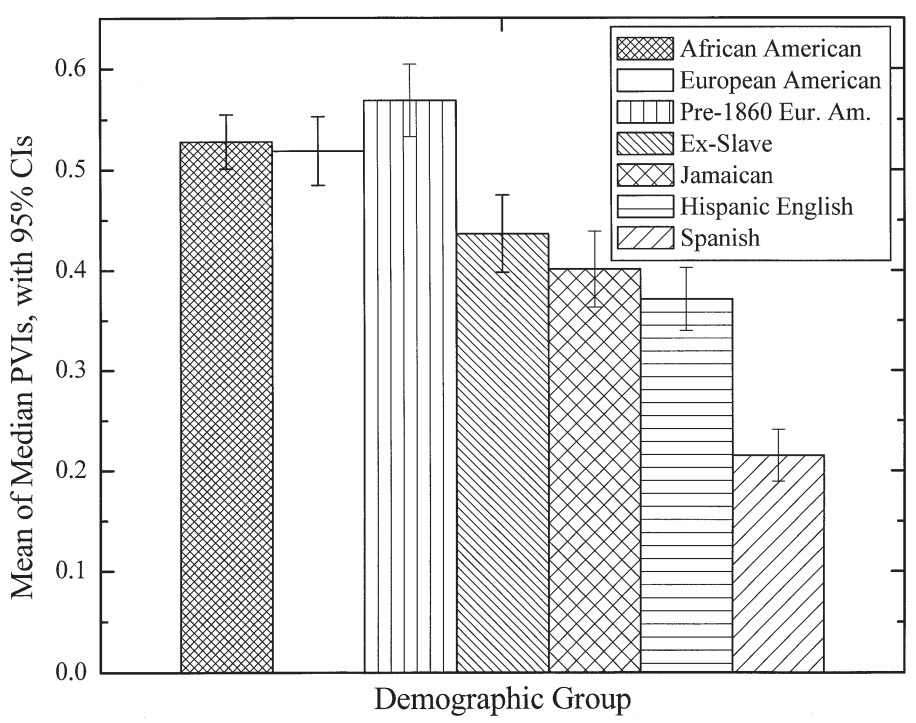

Figure 3. Bar graphs showing PVI scores for each demographic group. The error bars show $95 \%$ confidence intervals

distinguishing factor for contemporary AAE and EAE in North Carolina. Mean values were .5280 for African Americans and .5187 for European Americans. A 2-tailed t-test for the two groups assuming unequal variances yields the same result $(\mathrm{t}=0.4512, \mathrm{df}=36, p=.6546)$.

The position of the ex-slaves is striking. Although their $95 \%$ confidence interval overlaps those of Jamaicans and Hispanic L2 English speakers, it does not overlap at all those of the younger African Americans, younger European Americans, or, most notably, pre-Civil War European Americans. This result suggests that a difference in rhythm may have existed between earlier AAE and earlier Southern EAE and that AAE has become more stress-timed over the years. The notion that AAE has become more stress-timed is corroborated by Figure 4, which plots the PVI scores for all the African Americans examined against their year of birth. A clear upward trend in PVI values is obvious, and the slope of the regression line is significant at $p=.0009349$. The regression line may not describe the overall distribution perfectly, since there is a rather sharp break between speakers born in the 19th century and those born in the 20th century. However, it demonstrates that a change occurred in AAE.

The PVI formula is designed to control for the overall rate of speech. However, it is conceivable that the rate of speech could interact with rhythm. For that reason, we examined the rate of speech by calculating the median syllable duration for the syllables used in the PVI calculations. We excluded pre-pausal 


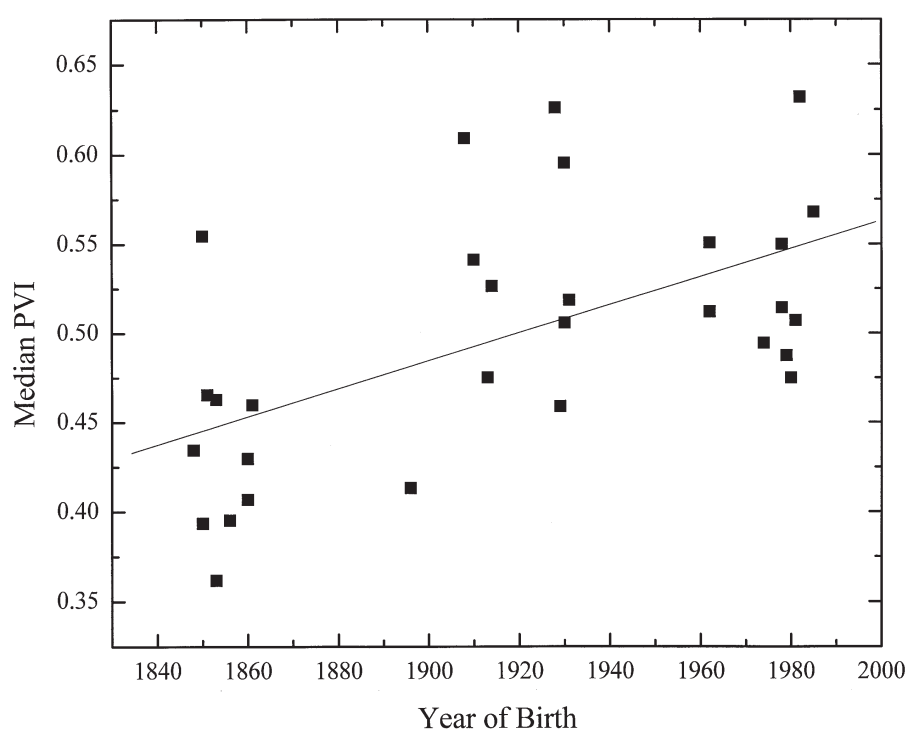

Figure 4. Plot of year of birth against median PVI scores for African American speakers, including all ex-slaves except Wallace Quarterman. The slope of the regression line is significant at $p=.0009349$

feet, limiting duration calculations to the syllables used for PVI calculations. Figure 5 shows the median syllable durations for each speaker plotted against the speaker's year of birth. Spanish shows the lowest median syllable durations, probably because Spanish does not typically utilize length distinctions, while English vowels show intrinsic length distinctions as well as differences in length between stressed and unstressed vowels. Hispanic L2 speakers of English tend to show low values as well, though the Jamaicans and the ex-slaves varied widely. Other African Americans also showed a broad range of variation, but European Americans varied more than any other group.

A slight downward trend seems discernible among the scores for European Americans in Figure 5. Such a trend, if real, could result from three possible factors. First, there is some evidence that aging decreases the overall rate of speech (Mysak and Hanley 1958; Benjamin 1982; Smith, Wasowitz and Preston 1987). This effect, obviously, is an age-grading phenomenon. Second, it is possible that it represents a stylistic effect due to relative differences in age between the young interviewers and older interviewees. It is known that young and elderly people modify their speech style when speaking to each other (Giles et al. 1992), and a change in rate of speech could be one manifestation of this style shifting. A third possibility is that it reflects a decline in the "Southern drawl", the tendency for certain syllables to exhibit prolongation, vowel breaking, and 


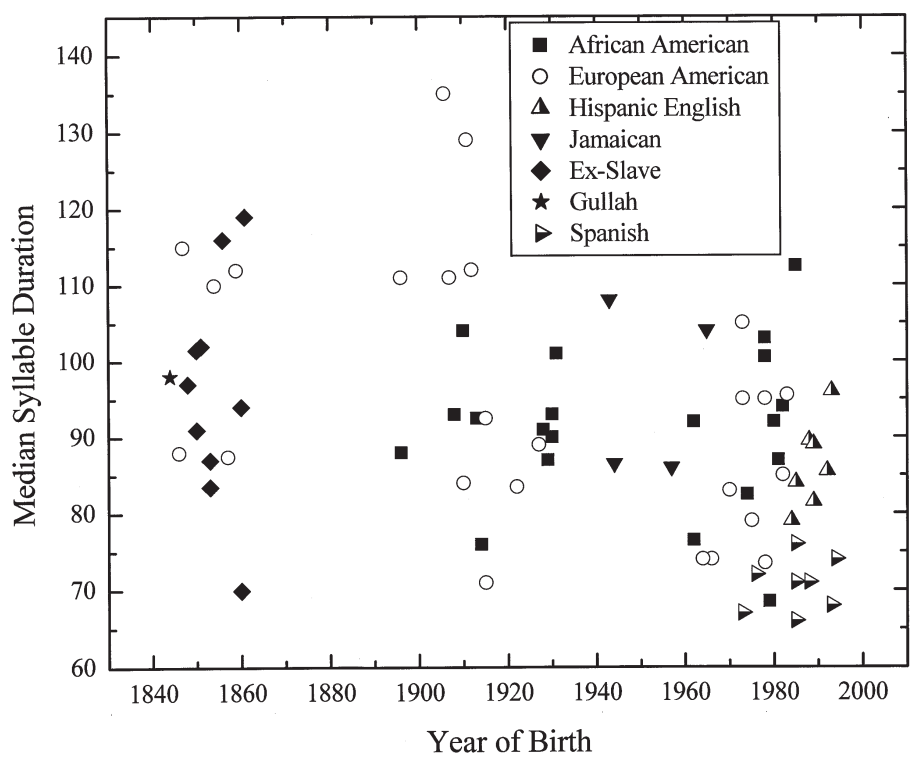

Figure 5. Median syllable durations for all speakers analyzed

wide intonational contours in dialects of the American South (e.g. Wise 1933; Feagin 1987; Wetzell 2000). This effect would be a diachronic difference. We offer no additional evidence for any of these possibilities, but because the trend is diminished or absent altogether among African Americans, it does not affect our conclusions with regard to rhythm. Nevertheless, these potentially confounding factors should be kept in mind by researchers investigating rhythm.

The relationship between overall rate of speech and rhythm is evident in Figure 6. Figure 6 plots the median duration of syllables used for PVI calculations, which reflects rate of speech, against median PVI scores for each speaker. The demographic groups appear to sort into two basic distributional types. For African Americans born in the 20th century and for European Americans, rate of speech seems to have no effect on rhythm. Speakers in these groups are arranged in a broad band across the graph that is distributed along the horizontal line inside the graph. Conversely, for the Spanish speakers, Hispanic L2 English speakers, Jamaicans, and the sole Gullah speaker, PVI increases with increasing syllable duration. Speakers in those groups are arranged along the diagonal line within the graph. The ex-slaves exhibit an ambiguous position with respect to the two distributional types, as if they represent a transition from the latter type to the former. 


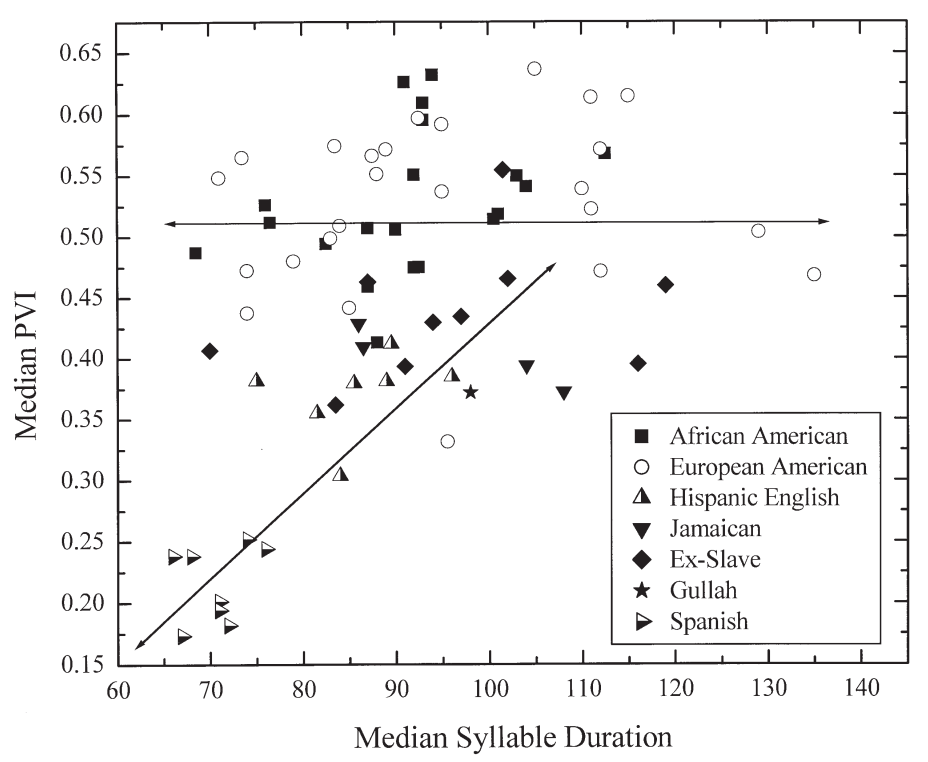

Figure 6. Plot of median syllable duration vs. median PVI scores for all speakers analyzed

\section{Discussion}

The lack of any significant difference between contemporary African Americans and European Americans in our sample with regard to stress-timing and syllable-timing indicates that rhythm is not diverging at all for the two ethnicities. Both show strongly stress-timed speech as a rule. The convergence appears for both of the birth cohorts (1896-1931 and 1961-1985) that we examined, indicating that it was in place throughout the 20th century. This finding bears on the Convergence / Divergence Controversy, the question of whether African American and European American vernaculars are becoming more or less like each other. While the work of William Labov, Guy Bailey, and others (see especially Fasold et al. 1987, and the response in Butters 1989) has found divergence for such features as vowel quality, narrative $-s$, and habitual be + -ing, the degree of stress-timing vs. syllable-timing does not supply any such evidence. If, as the ex-slave data suggest, AAE was once more syllable-timed, rhythm would represent a feature for which the two ethnicities have converged.

John Rickford, in Fasold et al. (1987), describes a number of different scenarios for the relationship between AAE and European American vernaculars: One variety could diverge or converge while the other variety is static, or both could converge or diverge. He also notes that different time periods could show 
different patterns, such as a period of convergence followed by a period of divergence or alternating patterns of convergence, equidistance, and divergence. Guy Bailey, an advocate of the convergence-followed-by-divergence scheme, has suggested (p.c.) that most of the convergent features, such as merger of /I/ and $/ \varepsilon /$ before nasals, are developments that were underway during the late 19th century, while most divergent features, such as the different vowel shifting patterns and be + -ing, did not begin until the 20th century. The data shown in Figures 2 and 4 suggest that, if AAE and EAE differed for rhythm at one time, the convergence was probably underway before 1900 - in fact, it was already completed among speakers born just after 1900.

The rhythm data provide evidence relevant to the Creolist / Anglicist Controversy. This controversy concerns the origin of AAE, with the most extreme creolists arguing that AAE is derived from a former creole spoken on plantations and the most extreme Anglicists arguing that all features of AAE are derived from dialectal variants found in the British Isles. If the pattern shown by the ten ex-slaves analyzed here represents the true nature of earlier AAE rhythm, then rhythm could shed some light on the origins of AAE. The fact that the median values of the ten ex-slaves barely overlapped those of the five European American Southerners born before the Civil War and the fact that the $95 \%$ confidence intervals for those two groups did not overlap suggest that earlier AAE was more syllable-timed than earlier Southern EAE. However, it should be emphasized that conclusions based on this relatively small sample of speakers from diverse areas have to be tentative.

There are two plausible sources of syllable-timing in early AAE. As for one, Caribbean creole influence, we have noted that Caribbean Anglophone speech is more syllable-timed than most other forms of English, and it can be added that large numbers of slaves were brought from the West Indies to the South, particularly to South Carolina (Winford 1997). The other possible source is African substrate influence. A difficulty here is that slaves originated in an extensive band stretching from modern-day Senegal to Angola and thus spoke a myriad of languages before they were enslaved. Furthermore, data on the rhythm of these languages is scarce. Nevertheless, it is quite possible that the vast majority of these languages were more syllable-timed than English. Abercrombie (1967) considers Yoruba to be syllable-timed, and the analysis in Gut et al. (2002), as noted earlier, shows three other West African languages to be more syllable-timed than English. Hence, syllable-timing could represent an areal feature of West African languages.

Nevertheless, there is little basis for determining whether creole influence, African substrate influence, or a combination of the two represents the source 
of syllable-timing in earlier AAE, if, indeed, earlier AAE was relatively syllable-timed. The PVI scores of most of the ex-slaves are similar to those of the Jamaicans. However, they are also similar to those of the Hispanic L2 English speakers, who show interference from a syllable-timed language (Spanish). Enslaved West Africans should likewise have shown interference from putatively syllable-timed West African languages. What is certain is that data from more speakers of earlier AAE, if recordings can be found, are desirable.

\section{Conclusions}

The results of our analysis indicate that contemporary African Americans and European Americans do not differ in the degree of stress-timing, at least in North Carolina. As far as the Convergence / Divergence Controversy is concerned, it appears to offer support for convergence. Nevertheless, if rhythm is seen as part of the larger domain of prosody, then it could be seen as part of a pattern in which, for each domain, some features are divergent and others are convergent. In the lexicon, for example, erstwhile African American slang such as hip and dis may be adopted by European Americans, even while both groups continue to develop new slang of their own. In vowel quality, Southern European Americans increasingly exhibit fronting of back vowels, which Southern African Americans have been slow or resistant to adopt (though see Fridland 2003) except in special circumstances (Childs 2005), but both show older Southern vowel developments such as glide weakening of /ai/ and rounding of the vowel in words such as car, start, and arm. Within prosody, differences are known in intonation (Tarone 1973; Loman 1975; Jun and Foreman 1996; Green 2002; Wolfram and Thomas 2002) even though we found none for rhythm in contemporary speech of the two ethnic groups. Further analyses, e.g. of pre-pausal feet or of durations of the consonantal parts of utterances, could reveal other prosodic differences or similarities.

We did find some indication, however, that AAE has not always agreed with EAE for rhythm. The evidence from the ex-slave recordings suggests that AAE has become more stress-timed diachronically. When coupled with evidence from the recordings of European American Southerners born before the Civil War, it suggests a former difference in rhythm between the two ethnicities. Whether relative stress-timing in earlier AAE stems from creole influence, either from a Gullah-like earlier form or from Caribbean creoles, or from direct substrate influence from West African languages, is impossible to say. Nonetheless, our findings for earlier AAE should be taken cautiously, considering 
the small corpus of ex-slaves and pre-Civil War European Americans and the fact that only one of them came from North Carolina, the home state of our contemporary speakers.

The differing provenances of the ex-slaves and our sample of contemporary African Americans bring to mind another unexplored issue with regard to rhythm in AAE, the possibility of variation in AAE rhythm in different parts of the South. The ex-slaves we analyzed did not show any rhythm differences that could be ascribed to regional variation. The ex-slave with the lowest score was Laura Smalley, from Texas, but the other Texans showed more modal scores. The highest score was from an Alabamian, Joe McDonald, but the other Alabamians, Isom Moseley and Alice Gaston, had considerably lower scores. Even so, the Antebellum South covered several different agricultural zones, each one with its own patterns of slavery. Ignoring areas such as the mountains where slavery never prevailed, the main areas consisted of the tobacco belt in the Upper South, with relatively small concentrations of slaves; the cotton belt in the region from South Carolina to Texas, where large slaveholdings were more common; the rice and indigo belt of the "Low Country" along the South Carolina and Georgia coast, where Gullah was spoken and the often massive plantations were vacated by whites during mosquito season; and the sugarcane- and rice-producing area of southern Louisiana, where contact with syllable-timed French occurred. We had only Wallace Quarterman from the Low Country and no speakers from southern Louisiana, but it would not be surprising if some differentiation in rhythm had occurred in those regions. Another question relates to possible differentiation among European American dialects. Although it may be unlikely, it remains to be seen whether Northern European Americans differ at all in rhythm from Southern European Americans. Any such divergence would open the possibility for differentiation between Northern European Americans and Northern African Americans because of the latter group's Southern origin.

Rhythm analysis offers these possibilities as well as offering a new variable for examining both of the major controversies about AAE, the Convergence / Divergence Controversy and the Creolist / Anglicist Controversy. The Convergence / Divergence Controversy, unfortunately, has largely been forgotten over the past decade, yet it relates directly to how well African Americans are being integrated into larger society. Furthermore, it is an issue that could also be applied to societal relationships of Native Americans, Hispanics, and Asian Americans. Rhythm and other prosodic variables could help to revive interest in the Convergence / Divergence Controversy. Meanwhile, though the Creolist / Anglicist Controversy needs no revival, it has suffered from a too narrow 
focus on a few morphosyntactic variables: verbal $-s$ and other tense markers, copula absence, invariant be, and plural marking. Discussions of what pronunciation variables say about the history of AAE are rare (see Bailey and Thomas 1998, and Thomas and Bailey 1998, on vowel quality; Winford 1998: 102-3, on consonants; and Loman 1975, and Sutcliffe 2003, on prosody). Examination of additional phonetic and phonological variables, such as rhythm, would infuse the controversy with new data and, perhaps, new conceptualizations of the origins of AAE.

\section{References}

Abercrombie, David. 1967. Elements of General Phonetics. Edinburgh: Edinburgh University Press.

Ash, Sharon. 2003. "A national survey of North American dialects". In Dennis R. Preston, ed. Needed Research in American Dialects. Durham, NC: Duke University Press, 57-73.

Bailey, Guy, Natalie Maynor and Patricia Cukor-Avila, eds. 1991. The Emergence of Black English: Text and Commentary. Amsterdam, Philadelphia: Benjamins.

_ and Erik Thomas. 1998. "Some aspects of African-American Vernacular English phonology". In Salikoko S. Mufwene, John R. Rickford, Guy Bailey and John Baugh, eds. African-American English: Structure, History and Use. London, New York: Routledge, 85-109.

Benjamin, Barbaranne J. 1982. "Phonological performance in gerontological speech". Journal of Psycholinguistic Research 11: 159-67.

Bond, Zinny S. and Joann Fokes. 1985. "Non-native patterns of English syllable timing". Journal of Phonetics 13: 407-20.

Borzone de Manrique, Ana María and Angela Signorini. 1983. "Segmental duration and rhythm in Spanish". Journal of Phonetics 11: 117-28.

Butters, Ronald R. 1989. The Death of Black English: Divergence and Convergence in Black and White Vernaculars. Frankfurt am Main: Peter Lang.

Butterworth, Brian. 1980. "Evidence from pauses in speech". In Brian Butterworth, ed. Language Production. Vol. 1: Speech and Talk. London, New York: Academic, 155-76.

Carter, Phillip M. 2004. "The emergence of Hispanic English in the Raleigh community: A sociophonetic analysis". Unpublished M.A. thesis, North Carolina State University.

— 2005a. "Prosodic variation in SLA: Rhythm in an urban North Carolina Hispanic community". Penn Working Papers in Linguistics 11: 59-71.

_. 2005b. "Quantifying rhythmic differences between Spanish, English, and Hispanic English". In Randall S. Gess and Edward J. Rubin, eds. Theoretical and Experimental Approaches to Romance Linguistics. Amsterdam, Philadelphia: Benjamins, 63-75.

Childs, Rebecca L. 2005. "Investigating the local construction of identity: Sociophonetic variation in Smoky Mountain African American women's speech”. Ph.D. dissertation, University of Georgia. 
Dauer, R. M. 1983. "Stress-timing and syllable-timing reanalyzed". Journal of Phonetics 11: 51-62.

Deterding, David. 2001. "The measurement of rhythm: A comparison of Singapore and British English". Journal of Phonetics 29: 217-30.

Fasold, Ralph W., William Labov, Fay Boyd Vaughn-Cooke, Guy Bailey, Walt Wolfram, Arthur K. Spears and John Rickford. 1987. "Are Black and White vernaculars diverging? Papers from the NWAVE XIV panel discussion". American Speech 62: 3-80.

Feagin, Crawford. 1987. "A closer look at the Southern Drawl: Variation taken to extremes". In Keith M. Denning, Sharon Inkelas, Faye C. McNair-Knox and John R. Rickford, eds. Variation in Language: NWAV-XV at Stanford. Proceedings of the Fifteenth Annual Conference on New Ways of Analyzing Variation. Stanford, CA: Dept. of Linguistics, Stanford University, 137-50.

Fought, Carmen and John Fought. 2002. "Prosodic rhythm patterns in Chicano English". Typescript.

Fridland, Valerie. 2003. "Network strength and the realization of the Southern Vowel Shift among African Americans in Memphis, Tennessee”. American Speech 78: 3-30.

Giles, Howard, Nikolas Coupland, Justine Coupland, Angie Williams and J. Nussbaum. 1992. "Intergenerational talk and communication with older people". International Journal of Aging and Human Development 34: 271-97.

Green, Lisa J. 2002. African American English: A Linguistic Introduction. Cambridge: Cambridge University Press.

Gut, Ulrike. 2002. "Prosodic aspects of Standard Nigerian English”. In Gut and Gibbon, eds.: $167-78$.

— and Dafydd Gibbon, eds. 2002. Typology of African Prosodic Systems. Bielefeld: Bielefeld University.

__ Eno-Abasi Urua, Sandrine Adouakou and Dafydd Gibbon. 2002. "Rhythm in West African tone languages: A study of Ibibio, Anyi and Ega”. In Gut and Gibbon, eds.: $159-65$.

House, Arthur S. and Grant Fairbanks. 1953. "The influence of consonant environment upon the secondary acoustical characteristics of vowels". Journal of Speech and Hearing Research 5: 38-58.

Howell, Peter and Karima Kadi-Hanifi. 1991. "Comparison of prosodic properties between read and spontaneous speech material”. Speech Communication 10: 163-9.

Jun, Sun-Ah and Christina Foreman. 1996. "Boundary tones and focus realization in African-American intonation". Paper presented at the 3rd joint meeting of the Acoustical Society of America and the Acoustical Society of Japan, Honolulu, HI.

Klatt, Dennis H. 1975. "Vowel lengthening is syntactically determined in a connected discourse". Journal of Phonetics 3: 129-40.

Loman, Bengt. 1975. "Prosodic patterns in a Negro American dialect”. In Håkan Ringbom, Alfhild Ingberg, Ralf Norrman, Kurt Nyholm, Rolf Westman and Kay Wikberg, eds. Style and Text: Studies Presented to Nils Erik Enkvist. Stockholm: Språkförlaget Skriptor $\mathrm{AB}, 219-42$.

Low, Ee Ling and Esther Grabe. 1995. "Prosodic patterns in Singapore English”. In Kjell Elenius and Peter Branderud, eds. 1995. Proceedings of The XIIIth International Congress of Phonetic Sciences. Vol. 3. Stockholm: KTH and Stockholm University, 636-9. 
— $—$ and Francis Nolan. 2000. "Quantitative characterizations of speech rhythm: Syllable-timing in Singapore English". Language and Speech 43: 377-401.

Miller, M. 1984. "On the perception of rhythm". Journal of Phonetics 12: 75-83.

Mochizuki-Sudo, Michiko and Shigeri Kiritani. 1991. "Production and perception of stressrelated durational patterns in Japanese learners of English". Journal of Phonetics 19: 231-48.

Mysak, E.D. and T.D. Hanley. 1958. "Aging processes in speech: Pitch and duration characteristics”. Journal of Gerontology 13: 309-13.

Nguyen, Thi Anh Thu. 2003. "Prosodic transfer: The tonal constraints on Vietnamese acquisition of English stress and rhythm”. Unpublished Ph.D. dissertation, University of Queensland.

Peterson, Gordon E. and Ilse Lehiste. 1960. "Duration of syllable nuclei in English". Journal of the Acoustical Society of America 32: 693-703.

Pike, Kenneth L. 1945. The Intonation of American English. Ann Arbor: University of Michigan Press.

Ramus, Franck, Marina Nespor and Jacques Mehler. 1999. “Correlates of linguistic rhythm in the speech signal". Cognition 73: 265-92.

Rickford, John R. 1991. "Representativeness and reliability of the ex-slave narrative materials, with special reference to Wallace Quarterman's recording and transcript". In Bailey, Maynor and Cukor-Avila, eds.: 191-212.

Roach, Peter. 1982. 'On the distinction between 'stress-timed' and 'syllable-timed' languages". In David Crystal, ed. Linguistic Controversies: Essays in Linguistic Theory and Practice in Honour of F.R. Palmer. London: Edward Arnold, 73-9.

Schneider, Edgar W. 1996. "Introduction: Research trends in the study of American English". In Edgar W. Schneider, ed. Focus on the USA. Amsterdam, Philadelphia: Benjamins, $1-12$.

Smith, Bruce L., Jan Wasowicz and Judy Preston. 1987. "Temporal characteristics of the speech of normal elderly adults". Journal of Speech and Hearing Research 30: 522-9.

Spears, Arthur K. 1988. "Black American English”. In Johnnetta B. Cole, ed. Anthropology for the Nineties: Introductory Readings. New York: Free Press; London: Collier Macmillan, 96-113.

Spencelayh, Brendan. 2001. "Comparing rhythmic variation in four British dialects". Unpublished typescript.

Sutcliffe, David. 2003. "African American English supersegmentals: A study of pitch patterns in the Black English of the United States". In Ingo Plag, ed. Phonology and Morphology of Creole Languages. Tübingen: Niemeyer, 147-62.

Swerts, Marc, Eva Strangert and Mattias Heldner. 1996. " $\mathrm{F}_{0}$ declination in read-aloud and spontaneous speech". In Proceedings of the Fourth International Conference on Spoken Language Processing, Philadelphia, October 1996. Vol. 3. Piscataway, NJ: IEEE, 1501-4.

Tarone, Elaine E. 1973. "Aspects of intonation in Black English". American Speech 48: 29-36.

Thomas, Erik R. and Guy Bailey. 1998. "Parallels between vowel subsystems of African American Vernacular English and Caribbean Anglophone creoles". Journal of Pidgin and Creole Languages 13: 267-96. 
Udofot, Inyang. 2003. "Stress and rhythm in the Nigerian accent of English: A preliminary investigation". English World-Wide 24: 201-20.

Wells, J. C. 1982. Accents of English. Vol. 3: Beyond the British Isles. Cambridge: Cambridge University Press.

Wenk, Brian J. and François Wiolland. 1982. “Is French really syllable-timed?” Journal of Phonetics 10: 193-216.

Wetzell, Brett. 2000. "Rhythm, dialects, and the Southern drawl”. Unpublished M.A. thesis, North Carolina State University.

Winford, Donald. 1997. "On the origins of African American Vernacular English: A Creolist perspective. Part I: The sociohistorical background”. Diachronica 14: 305-44.

- 1998. "On the origins of African American Vernacular English: A Creolist perspective. Part II: Linguistic features". Diachronica 15: 99-154.

Wise, Claude Merton. 1933. “The Southern American drawl”. Le Maitre Phonétique, Third Series, vol. 48. Issue 44: 69-71.

Wolfram, Walt and Erik R. Thomas. 2002. The Development of African American English: Evidence from an Isolated Community. Oxford, U.K., Malden, MA: Blackwell.

\section{Authors' addresses}

Erik R. Thomas

Department of English

Box 8105

North Carolina State University

Raleigh, NC 27695-8105

USA

e-mail: ethomas@social.chass.ncsu.edu
Phillip M. Carter

Department of English

Box 90014

Duke University

Durham, NC 27708

USA

e-mail:phillip.carter@duke.edu 
